\title{
Cortical Plasticity Induction by Pairing Subthalamic Nucleus Deep-Brain Stimulation and Primary Motor Cortical Transcranial Magnetic Stimulation in Parkinson's Disease
}

\author{
Kaviraja Udupa, ${ }^{1 \star}$ Nina Bahl, ${ }^{1 *}$ Zhen Ni, ${ }^{1}$ Carolyn Gunraj, ${ }^{1}{ }^{-}$Filomena Mazzella, ${ }^{1,3}$ Elena Moro, ${ }^{1,4}$ Mojgan Hodaie, ${ }^{2}$ \\ Andres M. Lozano, ${ }^{2} \odot$ Anthony E. Lang, ${ }^{1}$ and $\odot$ Robert Chen ${ }^{1}$ \\ Edmond J. Safra Program in Parkinson's Disease, ${ }^{1}$ Division of Neurology and ${ }^{2}$ Division of Neurosurgery, Krembil Neuroscience Centre, Toronto Western \\ Research Institute, Toronto, Ontario M5T 2S8, Canada, ${ }^{3}$ Brain and Spinal Cord Rehabilitation Program, Toronto Rehabilitation, University Health Network, \\ University of Toronto, Toronto, Ontario M4G 3V9, Canada, and ${ }^{4}$ Service de Neurologie, CHU Grenoble, Joseph Fourier University, Grenoble 38041, France
}

Noninvasive brain stimulation studies have shown abnormal motor cortical plasticity in Parkinson's disease (PD). These studies used peripheral nerve stimulation paired with transcranial magnetic stimulation (TMS) to primary motor cortex (M1) at specific intervals to induce plasticity. Induction of cortical plasticity through stimulation of the basal ganglia (BG)-M1 connections has not been studied. In the present study, we used a novel technique of plasticity induction by repeated pairing of deep-brain stimulation (DBS) of the BG with M1 stimulation using TMS. We hypothesize that repeated pairing of subthalamic nucleus (STN)-DBS and M1-TMS at specific time intervals will lead to plasticity in the M1. Ten PD human patients with STN-DBS were studied in the on-medication state with DBS set to 3 Hz. The interstimulus intervals (ISIs) between STN-DBS and TMS that produced cortical facilitation were determined individually for each patient. Three plasticity induction conditions with repeated pairings ( 180 times) at specific ISIs ( $\sim 3$ and $\sim 23$ ms) that produced cortical facilitation and a control ISI of $167 \mathrm{~ms}$ were tested in random order. Repeated pairing of STN-DBS and M1-TMS at short ( $\sim 3 \mathrm{~ms})$ and medium ( $\sim 23 \mathrm{~ms}$ ) latencies increased M1 excitability that lasted for at least $45 \mathrm{~min}$, whereas the control condition (fixed ISI of $167 \mathrm{~ms}$ ) had no effect. There were no specific changes in motor thresholds, intracortical circuits, or recruitment curves. Our results indicate that paired-associative cortical plasticity can be induced by repeated STN and M1 stimulation at specific intervals. These results show that STN-DBS can modulate cortical plasticity.

Key words: deep-brain stimulation; hyperdirect pathway; intracortical circuits; motor cortical plasticity; subthalamic nucleus; transcranial magnetic stimulation

\section{Significance Statement}

We introduced a new experimental paradigm to test the hypothesis that pairing subthalamic nucleus deep-brain stimulation (STN-DBS) with motor cortical transcranial magnetic stimulation (M1-TMS) at specific times can induce cortical plasticity in patients with Parkinson's disease (PD). We found that repeated pairing of STN-DBS with TMS at short $(\sim 3$ ms $)$ and medium $(\sim 23$ $\mathrm{ms}$ ) intervals increased cortical excitability that lasted for up to $45 \mathrm{~min}$, whereas the control condition (fixed latency of $167 \mathrm{~ms}$ ) had no effects on cortical excitability. This is the first demonstration of associative plasticity in the STN-M1 circuits in PD patients using this novel technique. The potential therapeutic effects of combining DBS and noninvasive cortical stimulation should be investigated further.

\section{Introduction}

Neuronal plasticity refers to the ability of neurons to change their structure and functions in response to repeated stimuli and these

Received June 29, 2015; revised Nov. 8, 2015; accepted Nov. 14, 2015

Author contributions:K.U., E.M., M.H., A.M.L., A.E.L., and R.C. designed research; K.U., N.B., Z.N., C.A.G., and F.M. performed research; K.U., N.B., and R.C. analyzed data; K.U., N.B., Z.N., C.A.G., E.M., M.H., A.M.L., A.E.L., and R.C. wrote the paper.

This work was funded by the Canadian Institutes of Health Research. changes outlast the stimulation period (Bliss and Lomo, 1973; Butler and Wolf, 2007). Brain plasticity is believed to be the basis of many physiological functions such as learning and memory and is altered in several neurodegenerative disorders (Mattson, 1989; Palop et al., 2006; Leal and Yassa, 2013) including Parkin- 
Table 1. Demographic and clinical parameters of the study participants

\begin{tabular}{|c|c|c|c|c|c|c|c|c|}
\hline Subject & Age (y) & Sex & $\begin{array}{l}\text { Disease } \\
\text { duration (y) }\end{array}$ & $\begin{array}{l}\text { Time since } \\
\text { Surgery (y) }\end{array}$ & UPDRS $^{b}$ III & $\begin{array}{l}\text { Medication } \\
\left(\mathrm{LE}^{a} ; \mathrm{mg} / \mathrm{d}\right)\end{array}$ & $\begin{array}{l}\text { More improved } \\
\text { body side }\end{array}$ & $\begin{array}{l}\text { DBS parameters (intensity, } \\
\text { pulse width, frequency) }\end{array}$ \\
\hline 1 & 61 & M & 13 & 4 & 21 & 0 & Right & $2.9 \mathrm{~V}, 60 \mu \mathrm{s}, 185 \mathrm{~Hz}$ \\
\hline 2 & 64 & $M$ & 14 & 11 & 44.5 & 1000 & Right & $3.6 \mathrm{~V}, 60 \mu \mathrm{s}, 60 \mathrm{~Hz}$ \\
\hline 3 & 53 & M & 14 & 4 & 11.5 & 600 & Right & $2.8 \mathrm{~V}, 60 \mu \mathrm{s}, 185 \mathrm{~Hz}$ \\
\hline 4 & 63 & $M$ & 27 & 8 & 19 & 800 & Left & $3.5 \mathrm{~V}, 60 \mu \mathrm{s}, 185 \mathrm{~Hz}$ \\
\hline 5 & 69 & M & 28 & 8 & 18 & 1100 & Right & 3.7 V, $60 \mu \mathrm{s}, 185 \mathrm{~Hz}$ \\
\hline 6 & 61 & $\mathrm{~F}$ & 13 & 2 & 6 & 1500 & Right & $3.0 \mathrm{~V}, 60 \mu \mathrm{s}, 130 \mathrm{~Hz}$ \\
\hline 7 & 45 & M & 12 & 2 & 16 & 600 & Right & $3.2 \mathrm{~V}, 60 \mu \mathrm{s}, 185 \mathrm{~Hz}$ \\
\hline 8 & 57 & $M$ & 15 & 2 & 25 & 1400 & Right & 3.7 V, $60 \mu \mathrm{s}, 185 \mathrm{~Hz}$ \\
\hline 9 & 48 & $M$ & 17 & 4 & 23.5 & 600 & Right & $4.0 \mathrm{~V}, 60 \mu \mathrm{s}, 60 \mathrm{~Hz}$ \\
\hline 10 & 65 & $M$ & 14 & 3 & 21 & 800 & Right & $1.5 \mathrm{~V}, 60 \mu \mathrm{s}, 130 \mathrm{~Hz}$ \\
\hline Mean $\pm S D$ & $58.6 \pm 2.5$ & $9 \mathrm{M}, 1 \mathrm{~F}$ & $16.7 \pm 1.9$ & $4.8 \pm 1.0$ & $21.6 \pm 3.5$ & $840 \pm 138.4$ & 9 right, 1 left & - \\
\hline
\end{tabular}

${ }^{a} \mathrm{LE}$ was calculated using the following formula: $\mathrm{LE}=$ total dose of immediate release levodopa (with peripheral decarboxylase inhibitor $)+(0.75 \times$ dose of controlled-release levodopa $)+(100 \times$ dose of pramipexole $)+(16.7 \times$ dose of ropinirole).

${ }^{b}$ UPDRS motor score at the time of the study.

son's disease (PD) (Picconi et al., 2012; Beeler et al., 2013). Impaired plasticity has been demonstrated in the corticostriatal synapse in slice preparations of basal ganglia (BG) circuits (Picconi et al., 2003) and primary motor cortex (M1) (Guo et al., 2015) in animal models of PD and in the substantia nigra pars reticulata in PD patients (Prescott et al., 2009). At the systems level, cortical plasticity can be induced noninvasively using transcranial magnetic stimulation (TMS) (Chen and Udupa, 2009). Studies in PD have implicated maladaptive plasticity, especially in patients with levodopa-induced dyskinesia using paired associative stimulation (PAS) protocols (Bagnato et al., 2006; Morgante et al., 2006; Ueki et al., 2006; Schwingenschuh et al., 2010; Kishore et al., 2014; Udupa and Chen, 2013). Although most studies demonstrated impaired plasticity, some showed exaggerated plasticity (Bagnato et al., 2006) and the differences may be attributed to the clinical stages of the disease. PAS involves pairing of peripheral nerve stimulation and M1-TMS based on spike-timing-dependent plasticity (STDP) (Stefan et al., 2000). STDP is based on the principle that, when repeated pairs of presynaptic and postsynaptic inputs (peripheral electrical nerve stimulation and M1-TMS) arrive almost simultaneously and result in firing of the postsynaptic cell, the synapse is strengthened. The conventional PAS protocol does not examine the interactions between the $\mathrm{BG}$ and the M1.

DBS is an accepted treatment in moderate to advanced PD (Weaver et al., 2012; Odekerken et al., 2013; Schuepbach et al., 2013). However, the mechanisms of DBS are not fully understood (Udupa and Chen, 2015). A previous study found that M1 excitability is increased at 2 specific latencies at $\sim 3$ and $23 \mathrm{~ms}$ after subthalamic nucleus (STN)-DBS (Kuriakose et al., 2010). The short latency facilitation $(\sim 3 \mathrm{~ms})$ is likely due to antidromic activation of the cortical-STN pathways demonstrated by STNDBS in anesthetized rats (Li et al., 2007) and in an optogenetic study (Gradinaru et al., 2009), whereas the longer latency ( 23 $\mathrm{ms}$ ) may be due to orthodromic conduction through the indirect BG (striato-pallido-thalamo-cortical) pathway. However, induction of plasticity in the BG-M1 pathway based on STDP has not been demonstrated.

*K.U. and N.B. contributed equally to this work and performed statistical analysis for all data.

Correspondence should be addressed to Dr. Robert Chen, Edmond J. Safra Program in Parkinson's Disease, Division of Neurology, Toronto Western Hospital, 399 Bathurst Street, 7MC-411, Toronto, 0N M5T 2S8, Canada. E-mail: Robert.Chen@uhn.ca.

DOI:10.1523/JNEUROSCI.2499-15.2016

Copyright $\odot 2016$ the authors $\quad 0270-6474 / 16 / 360397-09 \$ 15.00 / 0$
The aim of the present study was to investigate whether STDP can be induced in PD patients by pairing STN-DBS and M1-TMS at specific time intervals that represent cortical activation by DBS. We hypothesize that repeated pairing of STN-DBS and M1-TMS at specific time intervals will lead to long-term potentiation (LTP)-like plasticity in the M1 in PD patients.

\section{Materials and Methods}

\section{Patients}

We studied 10 PD patients ( 9 men, 1 woman, aged $58.6 \pm 2.5$ years, range $45-69)$ with chronic ( $>1$ year) bilateral STN-DBS. Patients were recruited from the Movement Disorders Clinic at the Toronto Western Hospital. Their clinical characteristics are shown in Table 1. All patients continued to take their prescribed dopaminergic medications during the study. Because glutamatergic receptor blockers may interfere with the induction of plasticity, amantadine (glutamate receptor antagonist) was withheld in four patients taking this medication on the study days. All patients provided written informed consent for participation in the study. The University Health Network Research Ethics Board approved the protocol.

\section{DBS settings}

During DBS-TMS pairings, DBS on the side of greatest clinical benefit was set to the lowest possible frequency of $3 \mathrm{~Hz}$ ( $333 \mathrm{~ms}$ between pulses), which allowed for interstimulus intervals (ISIs) of up to $167 \mathrm{~ms}$ between single-pulse DBS and TMS. The clinically used pulse-width $(60 \mu \mathrm{s})$ and voltage $(1.5-4.0 \mathrm{~V})$ were used. DBS of the contralateral side was switched off throughout the experiment. The individual DBS parameters are shown in Table 1. DBS was switched OFF during cortical excitability assessments before and after the plasticity induction protocols.

\section{TMS settings}

M1 stimulation ipsilateral to STN-DBS was performed using a $7 \mathrm{~cm}$ "figure-of-eight coil" powered by a Magstim $200^{2}$ stimulator. The coil was placed over the motor cortex at the optimal location with handle of the coil backwards and at $\sim 45^{\circ}$ from the midsagittal line for eliciting motor evoked potential (MEP) in the contralateral first dorsal interosseous (FDI) hand muscle. The "hot spot" was determined by moving the coil in $0.5 \mathrm{~cm}$ increments around the presumed motor hand area to obtain the consistent and maximum FDI-MEP amplitude. The optimal position was marked on the scalp to ensure proper placement of the coil throughout the experiment.

\section{EMG recording}

Surface EMG was recorded from the FDI muscle using disposable $\mathrm{Ag}-$ $\mathrm{AgCl}$ electrodes in a belly-tendon arrangement with the reference electrode placed near the tendon at the metacarpophalangeal joint of the index finger. The EMG signal was amplified at $1 \mathrm{~K}$ (Intronix Technologies Model 2024F), band-pass filtered $(20 \mathrm{~Hz}-2.5 \mathrm{kHz})$, digitized at $5 \mathrm{kHz}$ by an analog-to-digital interface (Micro1401; Cambridge Electronics Design), and stored in a laboratory computer for offline analysis. The sub- 


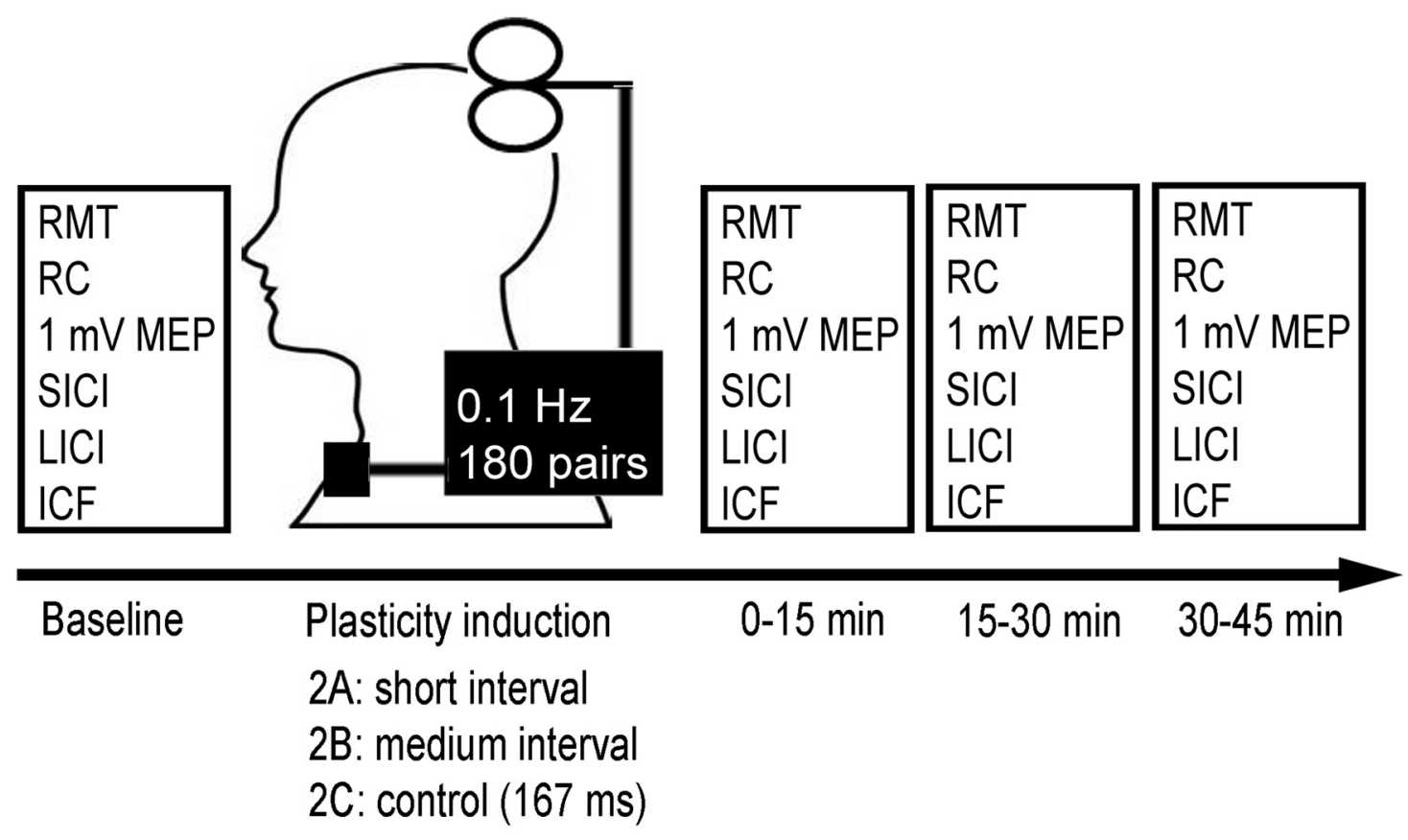

Figure 1. Experiment 2 setup. Three separate plasticity interventions were tested in which STN-DBS was paired with M1-TMS at $0.1 \mathrm{~Hz}$ for 30 min (180 pairs total). Each session varied in the ISI between DBS and TMS: Experiment 2A (short interval, $\sim 3 \mathrm{~ms}$ ), Experiment 2B (medium interval, $\sim 23 \mathrm{~ms}$ ), and the control interval (167 ms) were tested in each subject in a randomized order at least 1 week apart. RMT, RC (MEP amplitudes at 120\%, 140\%, and 160\% of RMT), MEP amplitudes at fixed intensity that evoked $1 \mathrm{mV}$ MEP and intracortical circuits (SICI, ICF, and LICI) were used as cortical excitability measures at baseline and at time intervals of $0-15,15-30$, and $30-45$ min after the plasticity induction protocols.

jects maintained muscle relaxation during the experiment. EMG signal was monitored on a computer screen and via loudspeakers to provide audiovisual feedback. Background EMG activities were recorded for at least $50 \mathrm{~ms}$ before TMS and trials with excessive background activity $(>$ mean \pm 2 SDs) were excluded from analysis.

\section{Experiment 1}

Determination of ISIs between STN-DBS and M1-TMS that lead to increased M1 excitability. This experiment was performed to establish the ISIs between STN-DBS and M1-TMS that produced increased M1 excitability individually for each patient. Baseline motor cortex excitability was established with 20 TMS pulses over the M1 adjusted to produce $\sim 1$ $\mathrm{mV}$ MEP amplitude in the relaxed FDI muscle with the STN-DBS switched off. To enable paired STN-M1 stimulation, the STN stimulation artifacts were recorded with surface electrodes placed over the pulse generator on the chest wall and were used to trigger TMS pulses every $6 \mathrm{~s}$ with a Micro1401 interface (Cambridge Electronics Design) controlled by Signal Software (version 4.07). The time between STN stimulation and M1-TMS randomly varied among the following ISIs: 3, 4, 5, 17, 18, $19,20,21,22,23,24,25$, and $167 \mathrm{~ms}$. The first 12 ISIs were included as potentially relevant latencies corresponding to peak MEP facilitation as described previously (Kuriakose et al., 2010); $167 \mathrm{~ms}$ (midpoint between two DBS pulses) was chosen as a control. The $167 \mathrm{~ms}$ ISI was tested in 6 of 10 patients. The ISIs were delivered in random order and repeated 10 times each. TMS intensities were adjusted to produce $1 \mathrm{mV}$ MEPs with TMS alone. MEP amplitudes were measured peak-to-peak and averaged for each ISI.

Effects of STN-DBS on motor pathways. To test whether the clinical STN-DBS setting elicited MEPs in the contralateral FDI muscle through direct current spread to the corticospinal tract, 200 trials of STN-DBStriggered EMG responses were averaged with the muscle at rest and at $20 \%$ of maximum voluntary contraction (MVC).

\section{Experiment 2}

Pairing STN-M1 stimulation to induce plasticity. Figure 1 shows the protocol used. This experiment involved three substudies (Experiments 2A, $2 \mathrm{~B}$, and $2 \mathrm{C}$ ) performed in random order on separate days at least 1 week apart to avoid potential carryover effects (Stefan et al., 2000). In each session, STN-DBS and M1-TMS were paired repeatedly at short or medium ISI with maximal facilitation (determined in Experiment 1 for each patient for Experiments 2A or 2B) or the control condition (Experiment $2 \mathrm{C}$, ISI of $167 \mathrm{~ms}$ ) to assess the effect of the plasticity protocol on cortical excitability. We delivered pairs of DBS-TMS at a frequency of $0.1 \mathrm{~Hz}$, similar to the original description of the PAS protocol (Stefan et al., 2000). We did not use higher frequencies of DBS-TMS pairing because TMS at $0.1 \mathrm{~Hz}$ has no effect on cortical excitability, but TMS at $0.9 \mathrm{~Hz}$ or higher changes cortical excitability (Chen et al., 1997). Because the frequency of DBS could only be lowered to $3 \mathrm{~Hz}$ and TMS pairing occurred once in every $10 \mathrm{~s}$, TMS was paired with STN-DBS once every 30 DBS pulses. Therefore, during $30 \mathrm{~min}$ of plasticity induction, there were 180 TMS pulses and 5400 DBS pulses. Resting motor threshold (RMT), MEP recruitment curve (RC, MEP amplitudes at 120, 140 and 160\% of RMT, 10 pulses at each intensity), MEP amplitudes at fixed intensity that evoked $1 \mathrm{mV}$ MEP at baseline and intracortical circuits [short interval intracortical inhibition (SICI), intracortical facilitation (ICF) and longinterval intracortical inhibition (LICI)] were used as cortical excitability measures at baseline and at $0-15,15-30$, and 30-45 min after the plasticity induction protocols. The $1 \mathrm{mV}$ MEP amplitude is regarded as the primary outcome measure of plasticity, in accordance with previous PAS studies (Stefan et al., 2000; Morgante et al., 2006). For all intracortical measures, the test stimuli (TS) were set at the intensity to generate $\sim 1$ $\mathrm{mV}$ MEP and were readjusted in the postintervention reassessments as needed. To evoke SICI, a subthreshold conditioning stimulus (CS, $80 \%$ RMT) preceded the TS by 2 ms. ICF was elicited with a subthreshold CS ( $80 \%$ RMT) preceding the TS by $10 \mathrm{~ms}$. To measure LICI, a suprathreshold CS (intensity to generate $\sim 1 \mathrm{mV}$ MEP) preceded the TS by $100 \mathrm{~ms}$. These paired-pulse paradigms were delivered in random order and repeated 10 times each, along with 10 TS-alone trials. MEP amplitudes were measured peak-to-peak, averaged, and expressed as a ratio of conditioned (CS-TS) to unconditioned (TS alone) MEP for each measure.

Because attention influences the magnitude of experimentally induced plasticity (Stefan et al., 2004), we directed subjects' attention to their stimulated hand during the plasticity intervention. Subjects received between 15 and 18 weak electrical stimuli (200\% of perceptual threshold) to their ring finger via ring electrodes throughout the 30 min plasticity 


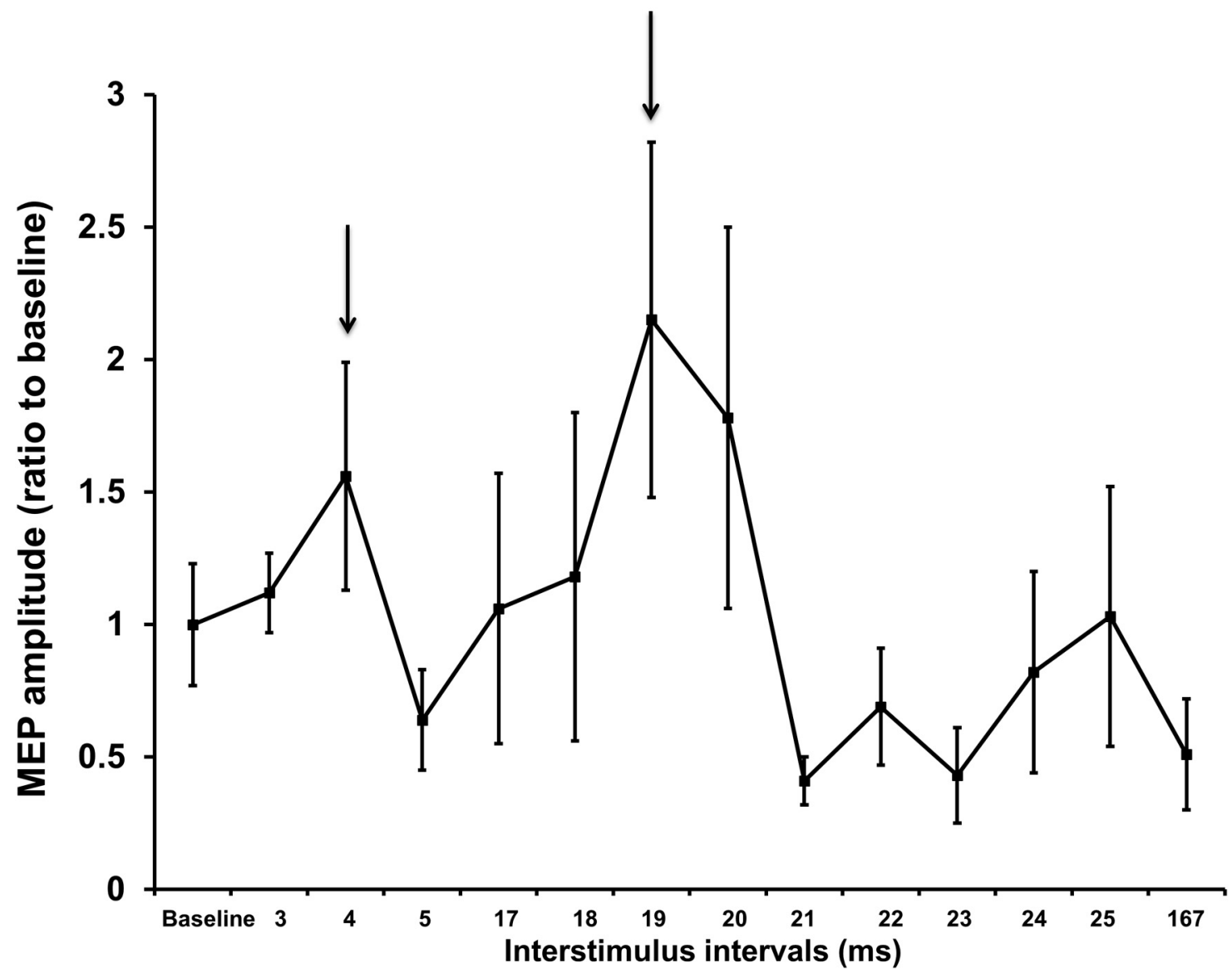

Figure 2. Example of an individual time course of M1 excitability after single-pulse STN-DBS paired with M1-TMS. Findings from patient 7 in Experiment 1 are shown. The mean MEP amplitude at each time interval after STN stimulation is expressed as a ratio to the mean baseline MEP amplitude (20 TMS pulses over the M1 adjusted to produce $\sim 1 \mathrm{mV}$ MEP amplitude with STN-DBS switched off). Ratios $>1$ indicate facilitation and ratios $<1$ indicate inhibition of MEP amplitude. Error bars represent SEM. Two peaks of MEP facilitation were observed at 4 and $19 \mathrm{~ms}$ (arrows) in this patient.

protocol. They were instructed to count and report this number upon conclusion of the intervention. To control for diurnal variability in plasticity responses (Sale et al., 2008), the experimental sessions were administered in the afternoon for all subjects.

\section{Data analysis}

Statview 5.0.1 software (SAS Institute) was used for all statistical analyses. Significance was set at $p<0.05$ and, unless otherwise stated, data are reported as mean \pm SEM. Fisher's protected least square difference post hoc tests were performed as appropriate.

Experiment 1. For each ISI, MEP amplitudes were expressed as a ratio to the mean baseline MEP. The time courses were evaluated by visual inspection individually to determine the times for the peaks of MEP facilitation for each patient. A paired $t$ test was performed on the group data to evaluate differences between the baseline MEP and MEP amplitude at short, medium, and $167 \mathrm{~ms}$ after single-pulse STN-DBS (control ISI).

Experiment 2. Two-way repeated measures of ANOVA (RM-ANOVA) were performed on the $1 \mathrm{mV}$ MEP amplitude data with intervention (three intervals: short, medium, control) and postintervention time (three periods: $0-15,15-30,30-45 \mathrm{~min}$ ) as the within-subject factors. If the main effects were significant, post hoc analysis was performed using Fisher's protected least square difference test. Three-way RM-ANOVA was performed on recruitment curve data with intervention (three intervals: short, medium, control), postintervention time (three levels: 0-15, 15-30, 30-45 min), and stimulator intensity (three levels: $120 \%, 140 \%$, and $160 \%$ of RMT) as the within-subject factors. The $1 \mathrm{mV}$ MEP and MEP recruitment curve data were expressed as ratios to the mean baseline MEP amplitude to account for interindividual variability in MEP amplitudes at baseline. Two-way RM-ANOVA was performed on RMT and intracortical circuits (SICI, LICI, and ICF) data with sessions (three intervals: short, medium, control) and time (four levels: baseline and $0-15,15-30,30-45 \mathrm{~min}$ postintervention) as within-subject factors. If changes in $1 \mathrm{mV}$ MEP amplitude or MEP recruitment curve were significant, a linear regression was performed to evaluate the relationship between the magnitude of induced cortical plasticity and different clinical PD features: (1) Unified Parkinson's disease rating scale (UPDRS) score improvement from STN-DBS surgery [difference between preoperative score (OFF medication) and postoperative score near time of study (OFF medication/ON stimulation)], (2) UPDRS scores at the time of study (ON medication/ON stimulation), (3) hemi-UPDRS scores at the time of study (ON medication/ON stimulation) for the body side studied, (4) medications dosage (levodopa equivalent), (5) disease duration, and (6) time since STN-DBS surgery.

\section{Results}

Experiment 1

Individual time courses of M1 excitability were examined after DBS-TMS pairings to determine the ISIs at which peak MEP facilitation occurred. A representative example is shown in Figure 2. We observed two peaks of cortical facilitation at short (3-5 ms) and medium (18-25 ms) intervals between STN-DBS and M1TMS in all subjects. The peaks ISIs for each patient are shown in Table 2 and were used in Experiment 2. MEP amplitude increased at short $(2.64 \pm 0.36 \mathrm{mV} ; p=0.008$, paired $t$ test $)$ and medium (3.08 $\pm 0.53 \mathrm{mV} ; p=0.002$, paired $t$ test) latencies compared with baseline MEP amplitude $(1.27 \pm 0.08 \mathrm{mV})$. However, 167 ms after single-pulse STN-DBS (MEP amplitude $1.44 \pm 0.48$ 
Table 2. ISIs (between STN-DBS and M1-TMS) producing two peaks of M1 excitability in Experiment 1

\begin{tabular}{lll}
\hline Subject & Short-interval (ms) & Medium-interval (ms) \\
\hline 1 & 4 & 23 \\
2 & 3 & 22 \\
3 & 3 & 18 \\
4 & 3 & 19 \\
5 & 4 & 25 \\
6 & 3 & 22 \\
7 & 4 & 19 \\
8 & 5 & 21 \\
9 & 5 & 22 \\
10 & 3 & 25 \\
Mean & 3.7 & 21.6 \\
Range & $3-5$ & $18-25$ \\
\hline
\end{tabular}

$\mathrm{mV})$, MEP amplitude was not significantly different compared with baseline MEP amplitude ( $p=0.74$, paired $t$ test). Because the $167 \mathrm{~ms}$ ISI had no effect on M1 excitability, we designated this interval as a control (Experiment 2C) in investigating the plasticity effects. STN-DBS alone did not evoke any MEPs while the patients were at rest or during 20\% MVC. Therefore, there was no direct activation or current spread to corticospinal tract with the DBS parameters that we tested.

\section{Experiment 2}

Intensities used to generate $1 \mathrm{mV}$ MEP amplitudes were in the range of $49-63 \%$ of maximum stimulator output $(110-125 \%$ of RMT) and MEP amplitudes produced by $120 \%$ RMT were in the range of $0.87-1.23 \mathrm{mV}$. Figure 3 depicts the effects of the plasticity induction protocols on $1 \mathrm{mV}$ MEP. RM-ANOVA revealed a significant effect of plasticity intervention $(F=3.9, p=0.03)$ on MEP amplitude, with no significant effect of postintervention time or intervention $\times$ postintervention time interaction. Post hoc analysis revealed a significant increase in MEP amplitude at short $(p=0.05)$ and medium $(p=0.04)$ intervals compared with baseline, but there was no significant difference between the control interval and baseline. Increased MEP amplitude was observed in 7 of 10 subjects at the short ISI and in 8 of 10 subjects at the medium ISI in the postintervention time blocks. Therefore, the plasticity protocol increased M1 excitability after DBS-TMS pairs at short $(\sim 3 \mathrm{~ms})$ and medium $(\sim 23 \mathrm{~ms})$ ISIs for a sustained period of time ( $\geq 45 \mathrm{~min}$ ). No correlations were found between changes in $1 \mathrm{mV}$ MEP amplitude at short or medium ISIs and improvement in UPDRS scores from STN-DBS, UPDRS scores at the time of study, hemi-UPDRS scores from the side of body studied, medication dosage, disease duration, or time since surgery.

\section{Resting motor threshold and MEP recruitment curve after plasticity intervention}

RM-ANOVA showed a significant effect of time $(F=4.7, p=$ 0.009 ) on RMT after the plasticity protocols, but no significant effect of intervention or time $\times$ intervention interaction was found. Post hoc analysis revealed a significant decrease in RMT at postintervention time blocks of $0-15,15-30$, and 30-45 min compared with baseline. Because this decrease occurred regardless of the type of intervention (short: $43.5 \pm 2.4 \%$ at baseline vs $43.0 \pm$ $1.6 \%$ at $30-45 \mathrm{~min}$; medium: $45.3 \pm 1.5 \%$ at baseline vs $43.8 \pm$ $1.7 \%$ at $30-45 \mathrm{~min}$; control: $44.6 \pm 2.3 \%$ at baseline vs $42.3 \pm 1.9 \%$ at $30-45 \mathrm{~min}$ ), it is unlikely to represent a specific effect of the plasticity protocols tested. Figure 4 shows the effect of the plasticity protocols on the MEP recruitment curve. The effects of intervention, postintervention time, and TMS intensity were not significant, nor were the interactions between intervention $\times$ postintervention time, postintervention time $\times$ intensity, or intervention $\times$ postintervention time $X$ intensity. However, RM-ANOVA showed a trend toward significance for the intervention $X$ intensity interaction $(F=$ $2.3, p=0.07)$. Figure 4 shows that the MEP amplitudes for $120 \%$ RMT increased after the short- and medium-latency interventions, but for $160 \%$ RMT, there was little change in MEP amplitude after all three plasticity interventions.

\section{Intracortical circuits after plasticity intervention}

Figure 5 depicts the effect of the plasticity protocols on SICI (Fig. $5 A$ ), ICF (Fig. 5B), and LICI (Fig. 5C). Although ICF appeared to increase (short: $130.1 \pm 22 \%$ at baseline vs $165.6 \pm 21 \%$ at $30-45$ min; medium: $150.5 \pm 27 \%$ at baseline vs $185.0 \pm 17 \%$ at 30-45 min; control: $154.0 \pm 18 \%$ at baseline vs $195.9 \pm 22 \%$ at 30-45 $\mathrm{min}$ ) and LICI appeared to decrease (short: $21.0 \pm 9 \%$ at baseline vs $22.7 \pm 6 \%$ at $30-45 \mathrm{~min}$; medium: $16.8 \pm 5 \%$ at baseline vs $39.7 \pm 18 \%$ at $30-45 \mathrm{~min}$; control: $13.6 \pm 6 \%$ at baseline vs $36.8 \pm 20 \%$ at $30-45 \mathrm{~min}$ ) over time, these changes were not significant. RM-ANOVA revealed a significant effect of time on SICI only. Post hoc analysis showed a significant decrease in SICI during the 15-30 min (short: $66.9 \pm 12 \%$; medium: $111.6 \pm 23 \%$; control: $85.9 \pm 17 \%$ ) and $30-45 \mathrm{~min}$ (short: $82.4 \pm 16 \%$; medium: $97.5 \pm 21 \%$; control: $89.9 \pm 14 \%$ ) postintervention time blocks compared with baseline and the $0-15 \mathrm{~min}$ (short: $62.5 \pm 9 \%$; medium: $69.4 \pm 14 \%$; control: $63.8 \pm 11 \%$ ) postplasticity period.

\section{Discussion}

We tested a novel approach to induce LTP-like effects in the M1 by repeated pairing of STN-DBS and M1-TMS at specific time intervals that represented cortical activation by DBS. This is the first study to examine associative plasticity between the STN and M1.

\section{Short-latency peaks and pathways involved}

We observed short-latency MEP facilitation with TMS at 3-5 ms after single-pulse STN-DBS in PD patients (Fig. 2), in accordance with previous studies (Hanajima et al., 2004a; Kuriakose et al., 2010). Cortical evoked potentials recorded by electroencephalogram (EEG) were also observed at similar short latencies after STN-DBS in PD (Ashby et al., 2001; Baker et al., 2002; Hanajima et al., 2004a; MacKinnon et al., 2005; Walker et al., 2012). Animal studies demonstrated activation of the M1 at comparable latencies after STN-DBS in normal and parkinsonian animals (Li et al., 2007; Dejean et al., 2009; Gradinaru et al., 2009). It is likely that MEP facilitation after STN-DBS reflect STN-DBS activation of the M1 (Gradinaru et al., 2009). The short ( $>3 \mathrm{~ms}$ ) latency likely reflects activation of layer $\mathrm{V}$ neurons of the motor cortex through antidromic activation of the cortical-subthalamic hyperdirect pathway (Gradinaru et al., 2009). In the 6-hydroxydopamine rat model of PD, direct activation of layer $\mathrm{V}$ pyramidal neurons through antidromic activation of the hyperdirect pathway with STN stimulation has been demonstrated (Li et al., 2007; Dejean et al., 2009; Gradinaru et al., 2009). It has been proposed that layer II and III neurons are activated by TMS (Amassian et al., 1987; Huerta and Volpe, 2009; Di Lazzaro and Ziemann, 2013; Di Lazzaro and Rothwell, 2014), which in turn excites the pyramidal neurons in layer V. The possibility of collision between TMSevoked M1 volleys and DBS-induced antidromic volleys should also be considered. However, TMS activates corticospinal and other corticofugal neurons indirectly via an interneuron with a 


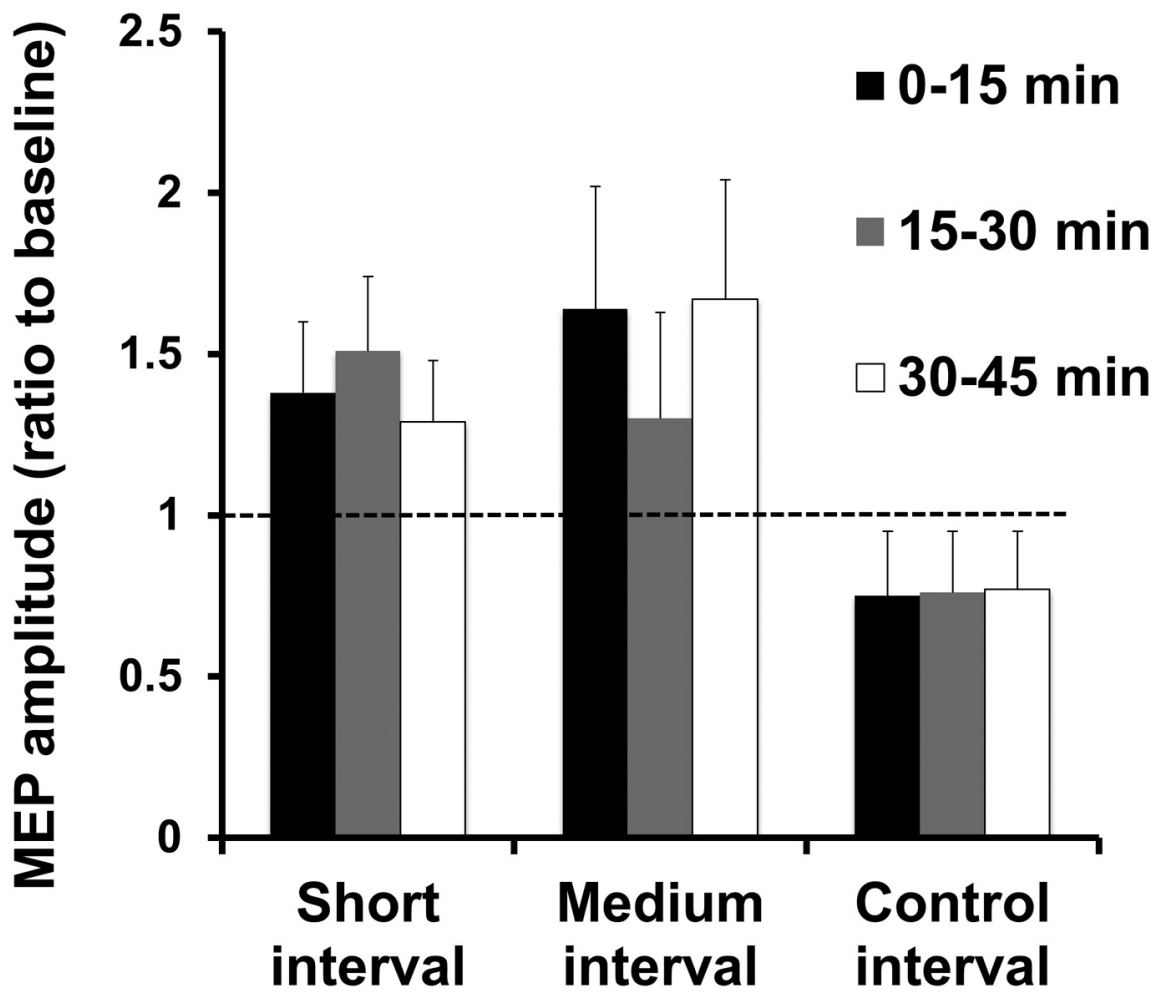

Figure 3. Effects of plasticity protocols on $1 \mathrm{mV}$ MEP amplitude at the three postintervention time blocks. The data are plotted as a ratio to the baseline MEP amplitude before the plasticity protocol. Ratios $>1$ indicate facilitation and ratios $<1$ indicate inhibition. Error bars represent SEM. The plasticity protocol increased mean MEP amplitudes at short $(\sim 3 \mathrm{~ms})$ and medium $(\sim 23$ ms) ISIs, but not at the control (167 ms) interval.

latency of $\sim 1.5 \mathrm{~ms}$ (Di Lazzaro and Ziemann, 2013). Therefore, the time from STN stimulation to activation of corticofugal neurons is $\sim 4.5 \mathrm{~ms}$ ( $3 \pm 1.5 \mathrm{~ms}$ ). This is longer than the time required for antidromic conduction from STN to M1, so collision was not likely to have occurred. Moreover, increased M1 excitability at the short intervals in Experiment 1 cannot be explained by collision. Therefore, the short latency $(\sim 3 \mathrm{~ms})$ of our study suggests that associative plasticity was induced by STN-DBS and M1-TMS in layer V of M1.

\section{Pathway for medium-latency} facilitation

We observed MEP facilitation at 18-25 ms after single-pulse STNDBS in PD patients (Fig. 2), in accordance with a previous study (Kuriakose et al., 2010). Cortical evoked potentials recorded by EEG were also observed at similar medium latencies after STN-DBS in PD (Baker et al., 2002; MacKinnon et al., 2005; Kuriakose et al., 2010; Walker et al., 2012). This medium-latency pathway probably involves polysynaptic projections from STN to M1 through the indirect pathways via the pallido-thalamo-cortical projections (Baker et al., 2002; MacKinnon et al., 2005; Kuriakose et al., 2010; Walker et al., 2012).

\section{Control experiment}

We chose ISI of $167 \mathrm{~ms}$ as the control interval because this is the longest ISI possible between DBS and TMS with DBS at $3 \mathrm{~Hz}$. We showed in Experiment 1 that this interval did not change cortical excitability. We used this interval as a control in Experiment 2 to determine whether the induction of associative plasticity is dependent on repeated, near synchronous activation of the motor cortex by STN-DBS and M1-TMS. All three interventions with short, medium, and control ISIs received the same amount of STN-DBS and M1TMS, with the timing (ISI) between STNDBS and M1-TMS being the only difference. Because there were no plasticity effects specific to this interval (Figs. 3, 4), we conclude that the plasticity effects of short- and medium-latency stimulation could not be attributed to the amount of STN-DBS and M1-TMS alone and likely involved STDP-associative plasticity induced by STN-DBS and M1-TMS at appropriate intervals.

\section{Possible current spread from DBS to corticospinal tract}

Because STN-DBS alone did not evoke any MEPs while at rest or during muscle activation, there was probably no direct activation of the corticospinal tract with the DBS parameters tested. Recordings from cervical epidural electrodes showed that TMS at intensities below the active motor threshold (AMT) did not produce recordable corticospinal waves (Di Lazzaro et al., 1998). Therefore, there is general acceptance that TMS at intensities below AMT do not activate the corticospinal pathway (Di Lazzaro et al., 2004). However, other methods, such as the H-reflex, may be more sensitive to detecting corticospinal activation. Stimulation of afferent fibers in the internal capsule is not likely because recording of median nerve somatosensory evoked potentials from the STN-DBS electrodes (Hanajima et al., 2004b) showed that they were not close to the sensory pathways.

\section{Features of plasticity induced by combining STN-DBS} and M1-TMS

The associative plasticity demonstrated in this study (facilitation of $\sim 50 \%$ above baseline) followed the characteristic features of plasticity such as temporal specificity (plasticity effects were specific to the intervals that produced cortical and did not occur with the control interval) and durability ( $>45 \mathrm{~min}$ ) (Bliss and Lomo, 1973; Stefan et al., 2000; Butler and Wolf, 2007). The plasticity could have been affected by impaired cortical plasticity in PD (Udupa and Chen, 2013).

Cortical activation pattern induced by associative plasticity The MEP recruitment curve at low intensities tests cortical excitability of a core group of neurons with the lowest activation threshold, whereas, at high intensities, recruitment curve examines neurons that are either less excitable or spatially further from the center of TMS activation (Chen, 2000). Figure 4 suggests that our plasticity protocols had greater effects on MEP elicited at low- than high-TMS intensities. This is consistent with the enhancement in M1 excitability demonstrated by increased $1 \mathrm{mV}$ $\mathrm{MEP}$ response because the MEP amplitudes were similar for the $120 \%$ RMT and the $1 \mathrm{mV}$ MEP conditions. We based the timing of the plasticity intervention on the optimal ISI for $1 \mathrm{mV}$ MEPs established in Experiment 1. Because high-intensity TMS activates wider cortical areas and leads to more late indirect (I) waves with longer latencies than low-intensity TMS (Chen, 2000; Di 
A Short interval ( 3ms)

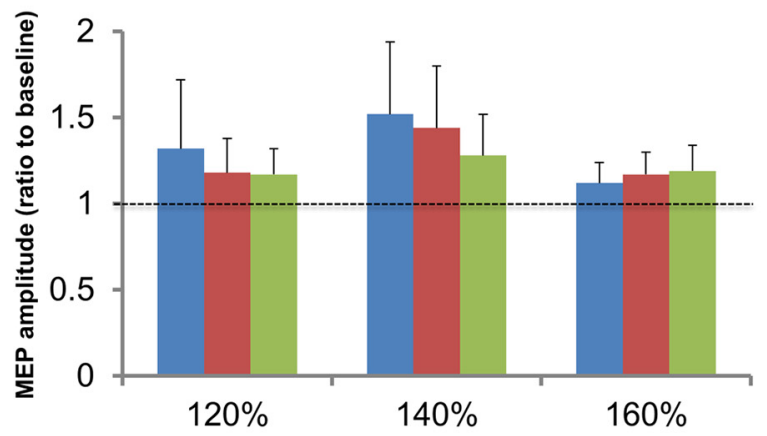

B Medium interval ( 23ms)

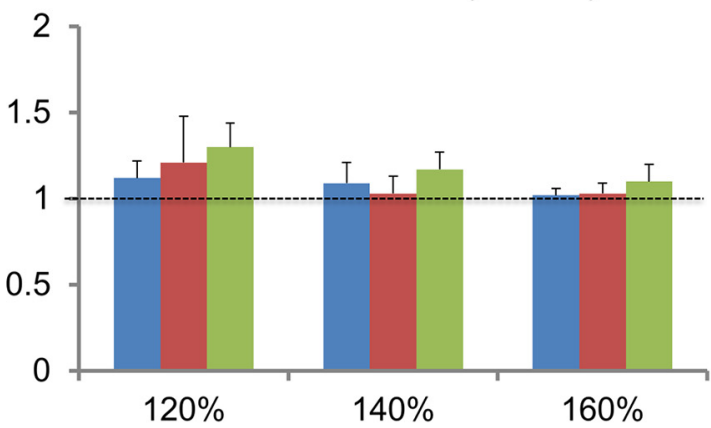

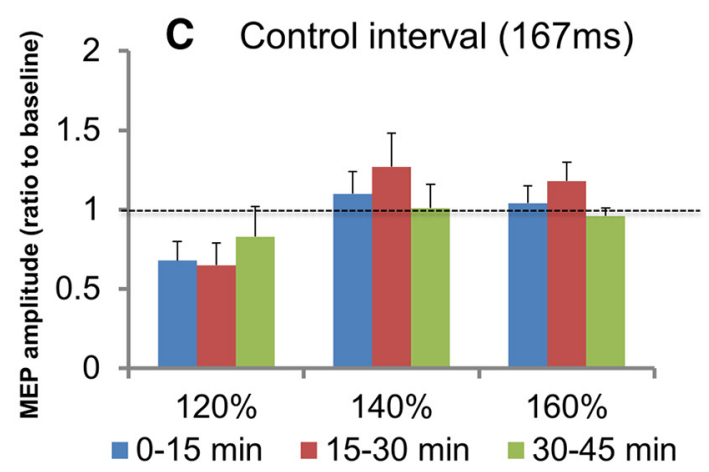

Figure 4. Effects of plasticity protocols on MEP recruitment curve at the three postintervention time blocks. The data are plotted as a ratio of the baseline MEP amplitude measured before the plasticity protocols at each stimulation intensity (expressed as percentage of RMT). Ratios $>1$ indicate facilitation and ratios $<1$ indicate inhibition. Error bars represent SEM. The results for the three plasticity interventions: short interval $(\sim 3 \mathrm{~ms} ; \boldsymbol{A})$; medium interval $(\sim 23 \mathrm{~ms} ; \boldsymbol{B})$, and control interval $(167 \mathrm{~ms} ; \boldsymbol{C})$ are shown on separate graphs. The analysis showed a trend toward significance for the intervention $\times$ stimulus intensity interaction $(p=0.07)$.
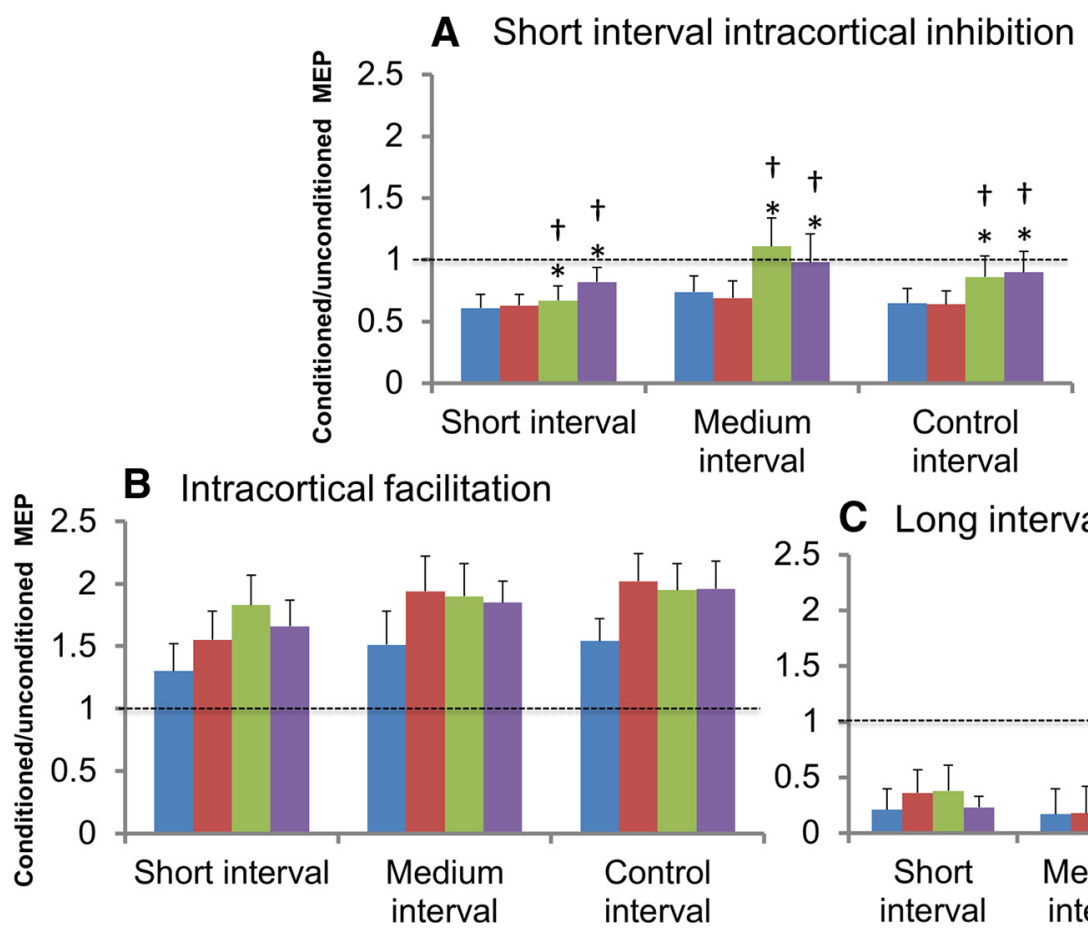

C Long interval intracortical inhibition

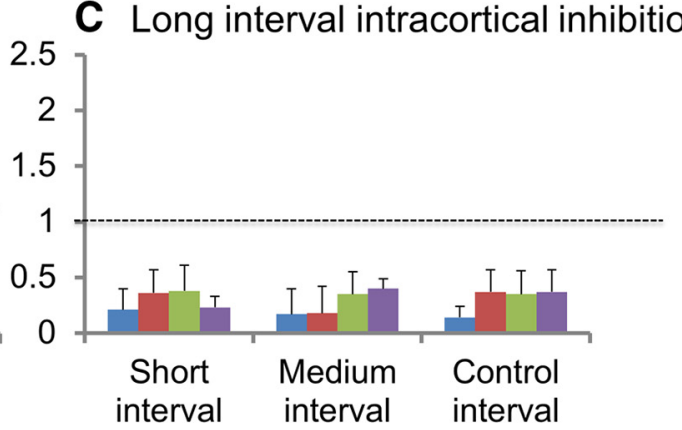

- Baseline $\approx$ 0-15 $\mathrm{min} \approx 15-30 \mathrm{~min}=30-45 \mathrm{~min}$

Figure 5. Intracortical circuit measures at baseline and at the three postintervention time blocks. The data are plotted as a ratio of conditioned to unconditioned MEP amplitude. Ratios $>1$ indicate facilitation and ratios $<1$ indicate inhibition. Error bars represent SEM. Analysis showed a significant effect of time on SICI $(\boldsymbol{A})$, but not on $(\boldsymbol{B})$ or LICI (C). SICI decreased during the $15-30$ min and 30 - 45 min postintervention time blocks after DBS-TMS pairings at short ( $\sim 3 \mathrm{~ms})$, medium ( $\sim 23 \mathrm{~ms})$, and control (167 ms) ISIs. ${ }^{*} p<0.05$ compared with baseline; $t p<0.05$ compared with $0-15 \mathrm{~min}$. 
Lazzaro and Ziemann, 2013; Di Lazzaro and Rothwell, 2014), plasticity induction combining STN-DBS with high-intensity TMS may require ISIs different from those tested and this will need to be tested in future studies.

\section{Intracortical circuit changes induced by associative plasticity} We found no changes in ICF and LICI after the plasticity interventions. SICI was decreased but was similar in all three plasticity protocols (Fig. 5). The decrease in SICI and RMT over time may be related to the duration of clinically ineffective STN-DBS. Although STN-DBS has been shown to decrease SICI (Cunic et al., 2002), the decrease in SICI after plasticity may not be specific to the induction of associative plasticity. This suggests that changes in SICI and RMT were due to nonspecific factors such as fatigue and lack of optimal stimulation during the study protocol and is consistent with the observation that PAS did not change SICI (Stefan et al., 2002).

\section{Limitations of the study}

We did not use clinical high frequencies $(130-185 \mathrm{~Hz})$ in our experiments because pairing M1-TMS is not feasible at high frequencies. During the plasticity intervention, DBS was set to the lowest possible frequency at $3 \mathrm{~Hz}$ and we choose $0.1 \mathrm{~Hz}$ for DBSTMS pairing based on previous PAS studies (Stefan et al., 2000; Morgante et al., 2006). This has potential confounding effects because of the $3 \mathrm{~Hz}$ DBS itself and due to the fact that only one TMS pulse was delivered for every 30 DBS. These factors might have reduced the effects that we observed, but cannot account for the plasticity effects for the short- and medium-ISI condition because the control condition (167 ms ISI) used the same DBS frequency. Amantadine has a longer half-life than levodopa. Four patients were on amantadine and only had overnight withdrawal. This might have reduced the plasticity effects that we observed. We did not observe correlation between clinical features and the plasticity effects and this may be related to the small sample size. Whether similar associative plasticity can be observed in conditions other than PD requires further study.

\section{Conclusions and future directions}

We provided the first demonstration of plasticity in the M1 induced by activities in the BG-M1 connection by repeated pairing of STN-DBS and M1-TMS at specific intervals. Our findings show that STN-DBS can modulate cortical plasticity. This is consistent with the finding that STN-DBS in the medication on state restored deficient cortical plasticity induced by PAS in dyskinetic PD patients (Kim et al., 2015). It has been shown that cortical activation coupled with STN stimulation required for motor function improvement in a rat model of PD and STN activation alone failed to bring this motor improvement (Gradinaru et al., 2009). Although we produced cortical activation with TMS, which is an unnatural external stimulus, it is conceivable that STDP may occur with high-frequency DBS and naturally occurring cortical activities. The therapeutic utility of costimulation of M1 with BG circuits may be investigated in future studies to further harness the plasticity effects.

\section{References}

Amassian VE, Stewart M, Quirk GJ, Rosenthal JL (1987) Physiological basis of motor effects of a transient stimulus to cerebral cortex. Neurosurgery 20:74-93. Medline

Ashby P, Paradiso G, Saint-Cyr JA, Chen R, Lang AE, Lozano AM (2001) Potentials evoked at the scalp by stimulation near the human subthalamic nucleus. Clin Neurophysiol 112:431-437. CrossRef Medline

Bagnato S, Agostino R, Modugno N, Quartarone A, Berardelli A (2006)
Plasticity of the motor cortex in Parkinson's disease patients on and off therapy. Mov Disord 21:639-645. CrossRef Medline

Baker KB, Montgomery EB Jr, Rezai AR, Burgess R, Lüders HO (2002) Subthalamic nucleus deep-brain stimulus evoked potentials: physiological and therapeutic implications. Mov Disord 17:969-983. CrossRef Medline

Beeler JA, Petzinger G, Jakowec MW (2013) The enemy within: propagation of aberrant corticostriatal learning to cortical function in Parkinson's disease. Front Neurol 4:134. Medline

Bliss TV, Lomo T (1973) Long-lasting potentiation of synaptic transmission in the dentate area of the anaesthetized rabbit following stimulation of the perforant path. J Physiol 232:331-356. CrossRef Medline

Butler AJ, Wolf SL (2007) Putting the brain on the map: use of transcranial magnetic stimulation to assess and induce cortical plasticity of upperextremity movement. Phys Ther 87:719-736. CrossRef Medline

Chen R (2000) Studies of human motor physiology with transcranial magnetic stimulation. Muscle Nerve Suppl 9:S26-S32. CrossRef Medline

Chen R, Udupa K (2009) Measurement and modulation of plasticity of the motor system in humans using transcranial magnetic stimulation. Motor Control 13:442-453. Medline

Chen R, Classen J, Gerloff C, Celnik P, Wassermann EM, Hallett M, Cohen LG (1997) Depression of motor cortex excitability by low-frequency transcranial magnetic stimulation. Neurology 48:1398-1403. CrossRef Medline

Cunic D, Roshan L, Khan FI, Lozano AM, Lang AE, Chen R (2002) Effects of subthalamic nucleus stimulation on motor cortex excitability in Parkinson's disease. Neurology 58:1665-1672. CrossRef Medline

Dejean C, Hyland B, Arbuthnott G (2009) Cortical effects of subthalamic stimulation correlate with behavioral recovery from dopamine antagonist induced akinesia. Cereb Cortex 19:1055-1063. CrossRef Medline

Di Lazzaro V, Rothwell JC (2014) Corticospinal activity evoked and modulated by non-invasive stimulation of the intact human motor cortex. J Physiol 592:4115-4128. CrossRef Medline

Di Lazzaro V, Ziemann U (2013) The contribution of transcranial magnetic stimulation in the functional evaluation of microcircuits in human motor cortex. Front Neural Circuits 7:18. Medline

Di Lazzaro V, Restuccia D, Oliviero A, Profice P, Ferrara L, Insola A, Mazzone P, Tonali P, Rothwell JC (1998) Magnetic transcranial stimulation at intensities below active motor threshold activates inhibitory circuits. Exp Brain Res 119:265-268. CrossRef Medline

Di Lazzaro V, Oliviero A, Pilato F, Saturno E, Dileone M, Mazzone P, Insola A, Tonali PA, Rothwell JC (2004) The physiological basis of transcranial motor cortex stimulation in conscious humans. Clin Neurophysiol 115: 255-266. CrossRef Medline

Gradinaru V, Mogri M, Thompson KR, Henderson JM, Deisseroth K (2009) Optical deconstruction of parkinsonian neural circuitry. Science 324: 354-359. CrossRef Medline

Guo L, Xiong H, Kim JI, Wu YW, Lalchandani RR, Cui Y, Shu Y, Xu T, Ding JB (2015) Dynamic rewiring of neural circuits in the motor cortex in mouse models of Parkinson's disease. Nat Neurosci 18:1299-1309. CrossRef Medline

Hanajima R, Ashby P, Lozano AM, Lang AE, Chen R (2004a) Single pulse stimulation of the human subthalamic nucleus facilitates the motor cortex at short intervals. J Neurophysiol 92:1937-1943. CrossRef Medline

Hanajima R, Dostrovsky JO, Lozano AM, Hutchison WD, Davis KD, Chen R, Ashby P (2004b) Somatosensory evoked potentials (SEPs) recorded from deep-brain stimulation (DBS) electrodes in the thalamus and subthalamic nucleus (STN). Clin Neurophysiol 115:424-434. CrossRef Medline

Huerta PT, Volpe BT (2009) Transcranial magnetic stimulation, synaptic plasticity and network oscillations. Journal of Neuroengineering and Rehabilitation 6:7. CrossRef Medline

Kim SJ, Udupa K, Ni Z, Moro E, Gunraj C, Mazzella F, Lozano AM, Hodaie M, Lang AE, Chen R (2015) Effects of subthalamic nucleus stimulation on motor cortex plasticity in Parkinson disease. Neurology 85:425-432. CrossRef Medline

Kishore A, Popa T, Balachandran A, Chandran S, Pradeep S, Backer F, Krishnan S, Meunier S (2014) Cerebellar sensory processing alterations impact motor cortical plasticity in Parkinson's disease: clues from dyskinetic patients. Cereb Cortex 24:2055-2067. Medline

Kuriakose R, Saha U, Castillo G, Udupa K, Ni Z, Gunraj C, Mazzella F, Hamani C, Lang AE, Moro E, Lozano AM, Hodaie M, Chen R (2010) The nature and time course of cortical activation following subthalamic 
stimulation in Parkinson's disease. Cereb Cortex 20:1926-1936. CrossRef Medline

Leal SL, Yassa MA (2013) Perturbations of neural circuitry in aging, mild cognitive impairment, and Alzheimer's disease. Ageing Res Rev 12: 823-831. CrossRef Medline

Li S, Arbuthnott GW, Jutras MJ, Goldberg JA, Jaeger D (2007) Resonant antidromic cortical circuit activation as a consequence of high-frequency subthalamic deep-brain stimulation. J Neurophysiol 98:3525-3537. CrossRef Medline

MacKinnon CD, Webb RM, Silberstein P, Tisch S, Asselman P, Limousin P, Rothwell JC (2005) Stimulation through electrodes implanted near the subthalamic nucleus activates projections to motor areas of cerebral cortex in patients with Parkinson's disease. Eur J Neurosci 21:1394-1402. CrossRef Medline

Mattson MP (1989) Cellular signaling mechanisms common to the development and degeneration of neuroarchitecture-a review. Mech Ageing Dev 50:103-157. CrossRef Medline

Morgante F, Espay AJ, Gunraj C, Lang AE, Chen R (2006) Motor cortex plasticity in Parkinson's disease and levodopa-induced dyskinesias. Brain 129:1059-1069. CrossRef Medline

Odekerken VJ, van Laar T, Staal MJ, Mosch A, Hoffmann CF, Nijssen PC, Beute GN, van Vugt JP, Lenders MW, Contarino MF, Mink MS, Bour LJ, van den Munckhof P, Schmand BA, de Haan RJ, Schuurman PR, de Bie RM (2013) Subthalamic nucleus versus globus pallidus bilateral deepbrain stimulation for advanced Parkinson's disease (NSTAPS study): a randomised controlled trial. Lancet Neurol 12:37-44. CrossRef Medline

Palop JJ, Chin J, Mucke L (2006) A network dysfunction perspective on neurodegenerative diseases. Nature 443:768-773. CrossRef Medline

Picconi B, Centonze D, Håkansson K, Bernardi G, Greengard P, Fisone G, Cenci MA, Calabresi P (2003) Loss of bidirectional striatal synaptic plasticity in L-DOPA-induced dyskinesia. Nat Neurosci 6:501-506. Medline

Picconi B, Piccoli G, Calabresi P (2012) Synaptic dysfunction in Parkinson's disease. Adv Exp Med Biol 970:553-572. CrossRef Medline

Prescott IA, Dostrovsky JO, Moro E, Hodaie M, Lozano AM, Hutchison WD (2009) Levodopa enhances synaptic plasticity in the substantia nigra pars reticulata of Parkinson's disease patients. Brain 132:309-318. Medline

Sale MV, Ridding MC, Nordstrom MA (2008) Cortisol inhibits neuroplasticity induction in human motor cortex. J Neurosci 28:8285-8293. CrossRef Medline

Schuepbach WM, Rau J, Knudsen K, Volkmann J, Krack P, Timmermann L,
Hälbig TD, Hesekamp H, Navarro SM, Meier N, Falk D, Mehdorn M, Paschen S, Maarouf M, Barbe MT, Fink GR, Kupsch A, Gruber D, Schneider GH, Seigneuret E, et al.; EARLYSTIM Study Group (2013) Neurostimulation for Parkinson's disease with early motor complications. N Engl J Med 368:610-622. CrossRef Medline

Schwingenschuh P, Ruge D, Edwards MJ, Terranova C, Katschnig P, Carrillo F, Silveira-Moriyama L, Schneider SA, Kägi G, Palomar FJ, Talelli P, Dickson J, Lees AJ, Quinn N, Mir P, Rothwell JC, Bhatia KP (2010) Distinguishing SWEDDs patients with asymmetric resting tremor from Parkinson's disease: a clinical and electrophysiological study. Mov Disord 25:560-569. CrossRef Medline

Stefan K, Kunesch E, Cohen LG, Benecke R, Classen J (2000) Induction of plasticity in the human motor cortex by paired associative stimulation. Brain 123:572-584. CrossRef Medline

Stefan K, Kunesch E, Benecke R, Cohen LG, Classen J (2002) Mechanisms of enhancement of human motor cortex excitability induced by interventional paired associative stimulation. J Physiol 543:699-708. CrossRef Medline

Stefan K, Wycislo M, Classen J (2004) Modulation of associative human motor cortical plasticity by attention. J Neurophysiol 92:66-72. CrossRef Medline

Udupa K, Chen R (2013) Motor cortical plasticity in Parkinson's disease. Front Neurol 4:128. Medline

Udupa K, Chen R (2015) The mechanisms of action of deep-brain stimulation and ideas for the future development. Prog Neurobiol 133:27-49. CrossRef Medline

Ueki Y, Mima T, Kotb MA, Sawada H, Saiki H, Ikeda A, Begum T, Reza F, Nagamine T, Fukuyama H (2006) Altered plasticity of the human motor cortex in Parkinson's disease. Ann Neurol 59:60-71. CrossRef Medline

Walker HC, Huang H, Gonzalez CL, Bryant JE, Killen J, Cutter GR, Knowlton RC, Montgomery EB, Guthrie BL, Watts RL (2012) Short latency activation of cortex during clinically effective subthalamic deep-brain stimulation for Parkinson's disease. Mov Disord 27:864-873. CrossRef Medline

Weaver FM, Follett KA, Stern M, Luo P, Harris CL, Hur K, Marks WJ Jr, Rothlind J, Sagher O, Moy C, Pahwa R, Burchiel K, Hogarth P, Lai EC, Duda JE, Holloway K, Samii A, Horn S, Bronstein JM, Stoner G, et al.; CSP 468 Study Group (2012) Randomized trial of deep-brain stimulation for Parkinson disease: thirty-six-month outcomes. Neurology 79:55-65. CrossRef Medline 